\title{
Malignant Peripheral Nerve Sheath Tumors-A Comprehensive Review of Pathophysiology, Diagnosis, and Multidisciplinary Management
}

\author{
Samantha W. E. Knight ${ }^{1}\left(\mathbb{D}\right.$, Tristan E. Knight ${ }^{2,3}{ }^{(D)}$, Teresa Santiago ${ }^{4}$, Andrew J. Murphy ${ }^{5,6}$ (D) \\ and Abdelhafeez H. Abdelhafeez ${ }^{5,6, *}$
}

1 Division of Surgery, Department of General Surgery, Southern Illinois University School of Medicine, Springfield, IL 62702, USA; sknight55@siumed.edu

2 Cancer and Blood Disorders Center, Seattle Children's Hospital, Seattle, WA 98195, USA; knight.tristan@gmail.com

3 Division of Hematology and Oncology, Department of Pediatrics, University of Washington School of Medicine, Seattle, WA 98195, USA

4 Department of Pathology, St. Jude Children's Research Hospital, Memphis, TN 38105, USA; Teresa.Santiago@STJUDE.ORG

5 Department of Surgery, St. Jude Children's Research Hospital, Memphis, TN 38105, USA; andrew.murphy@stjude.org

6 Division of Pediatric Surgery, Department of Surgery, University of Tennessee Health Science Center, Memphis, TN 38105, USA

* Correspondence: hafeez.abdelhafeez@stjude.org; Tel.: +1-(901)-595-2315; Fax: +1-(901)-595-2207

check for updates

Citation: Knight, S.W.E.; Knight, T.E.; Santiago, T.; Murphy, A.J.; Abdelhafeez, A.H. Malignant Peripheral Nerve Sheath Tumors-A Comprehensive Review of Pathophysiology, Diagnosis, and Multidisciplinary Management. Children 2022, 9, 38. https://doi.org/ $10.3390 /$ children 9010038

Academic Editor: Carl E. Stafstrom

Received: 22 November 2021 Accepted: 22 December 2021

Published: 1 January 2022

Publisher's Note: MDPI stays neutral with regard to jurisdictional claims in published maps and institutional affiliations.

Copyright: () 2022 by the authors Licensee MDPI, Basel, Switzerland. This article is an open access article distributed under the terms and conditions of the Creative Commons Attribution (CC BY) license (https:/ / creativecommons.org/licenses/by/ $4.0 /)$.

\begin{abstract}
Malignant peripheral nerve sheath tumors (MPNSTs) are aggressive soft tissue sarcomas (STS) with nerve sheath differentiation and a tendency to metastasize. Although occurring at an incidence of $0.001 \%$ in the general population, they are relatively common in individuals with neurofibromatosis type 1 (NF1), for whom the lifetime risk approaches $10 \%$. The staging of MPNSTs is complicated and requires close multi-disciplinary collaboration. Their primary management is most often surgical in nature, with non-surgical modalities playing a supportive, necessary role, particularly in metastatic, invasive, or widespread disease. We, therefore, sought to provide a comprehensive review of the relevant literature describing the characteristics of these tumors, their pathophysiology and risk factors, their diagnosis, and their multi-disciplinary treatment. A close partnership between surgical and medical oncologists is therefore necessary. Advances in the molecular characterization of these tumors have also begun to allow the integration of targeted RAS/RAF/MEK/ERK pathway inhibitors into MPNST management.
\end{abstract}

Keywords: malignant peripheral nerve sheath tumor; MEK inhibitor; multi-disciplinary management; neurofibroma; neurofibromatosis type 1

\section{Introduction}

Malignant peripheral nerve sheath tumors (MPNSTs) are malignant, locally aggressive soft tissue sarcomas (STS) with nerve sheath differentiation and a high propensity to metastasize. They are rare in the general population, with an approximate lifetime incidence of $0.001 \%$ (e.g., 1/100,000) [1]. However, in individuals with neurofibromatosis type 1 (NF1), the lifetime risk of developing one of these tumors is approximately $10 \%$. Up to $50 \%$ of all MPNSTs occur in patients with NF1 [1]. All-told, MPNST comprise 5-10\% of soft tissue sarcomas and are one of the most common nonrhabdomyosarcomatous soft tissue sarcomas (NRSTS) in pediatric patients [1]. Whereas about 10-20\% of all MPNSTs are diagnosed in children [1], there is no difference between children and adults in tumor location, size, or histological grade-although adults are more likely to have more than one primary tumor at the time of diagnosis [1]. 
MPNSTs may arise de novo from a peripheral nerve ORAs a malignant transformation of a pre-existing benign nerve sheath tumor-especially neurofibromas [2]. They may occur anywhere in the body but are most often axial in location and are diagnosed based on histopathological-demonstrated peripheral nerve sheath differentiation [2].

\section{Malignant Peripheral Nerve Sheath Tumors in Context as Soft Tissue Sarcomas}

MPNSTs are a form of sarcoma-that is, a tumor arising from cells of mesenchymal origin that have undergone malignant transformation. Mesenchymal cells display at least partial differentiation towards a connective tissue lineage-a broad term that includes, among others, muscle, adipose, bone, cartilage, vascular, and nervous tissue. Sarcomas are therefore classified based on the specific type of mesenchymal tissue they have arisen from and/or the tissue to which they bear a histopathological resemblance. Sarcomas are broadly divided into either soft tissue or bony tissue. Soft tissue sarcomas (STS) together comprise 7\% of pediatric solid tumors [3] and are divided into those which either display or do not display differentiation towards striated muscle: rhabdomyosarcomas and nonrhabdomyosarcomatous soft tissue sarcomas (NRSTS), respectively. The category of NRSTS contains a diverse array of sarcomas, as any STS which does not display striatedmuscle differentiation is necessarily included in this broad grouping.

According to the Fifth Edition of the World Health Organization (WHO)'s Classification of Tumors Soft Tissue and Bone Tumors, [4] nerve sheath tumors are divided into those which are benign (e.g., schwannomas, neurofibromas including plexiform neurofibromas, perineuriomas, etc.) and those which are malignant, of which MPNSTs form a major subset [5]. Although sometimes used synonymously with the terms "malignant schwannoma" or "neurofibrosarcoma," MPNST is the most accurate moniker, as these tumors may originate from and/or display differentiation towards any peripheral nerve sheath cell-not only Schwann cells [2].

\section{MPNST Pathophysiology}

Specific NRSTS may occur more commonly within the context of particular cancer predisposition syndromes (e.g., leiomyosarcoma in hereditary/germline retinoblastoma, due to RB1 mutation) [6]. Alternatively, certain NRSTS may be part of the diagnostic criteria for a given disorder (e.g., rhabdoid tumors in rhabdoid tumor predisposition syndrome, due to SMARCB1/INI1 mutation) [7]. MPNSTs are the former, as their presence does not specifically define the presence of Neurofibromatosis type 1 (NF1), nor are they required for its diagnosis. Still, they are considered a hallmark of NF1 when present. Similarly, many NRSTS are characterized by specific chromosomal translocations or mutations. The presence of such changes typically has one of two results. Firstly, a fusion protein may be generated, allowing for activation of a constitutively expressed kinase or transcription factor independent of ligand binding [8]. Secondly, the mutation may cause a deleterious loss-of-function in a tumor suppressor or cell-cycle regulator gene [9]. These alterations are detectable via polymerase chain reaction (PCR), and their presence helps to facilitate diagnosis within this heterogeneous group of tumors. MPNSTS are most often characterized by the second variety of mutations-specifically by loss of function of the tumor suppressor gene NF1.

Although bi-allelic NF1 inactivation or mutation appears necessary for MPNST development, it does not seem sufficient [10]. Plexiform neurofibromas were shown to develop in this context [11], but malignant transformation appears to require additional abnormalities-specifically, CDKN2A, EGFR, SUZ12, and TP53 have all been implicated [12]. EGFR, SUZ12, and TP53 mutations are all seen in the context of MPNSTs, but not in plexiform neurofibromas or atypical neurofibromas [12]. Similarly, CDKN2A loss is seen in the vast majority of atypical neurofibromas and in low-grade MPNSTs-but not in plexiform neurofibromas [13]. Therefore, one potential model for MPNST development proposes that bi-allelic NF1 loss occurs in nerve-sheath precursor cells, resulting in benign neurofibroma formation. Subsequently, loss of CDKN2A occurs, promoting the development of an atypi- 
cal neurofibroma-followed by additional mutations in EGFR, SUZ12, and/or TP53, which cause transformation into an MPNST [10].

\section{Relationship of MPNST to Neurofibromatosis Type 1}

NF1 is a neurocutaneous cancer predisposition syndrome, which may arise either de novo or be inherited in an autosomal dominant fashion. A diagnosis of NF1 may be established when an individual meets the National Institutes of Health diagnostic criteria (provided in Table 1). It is characterized by deleterious alterations in the NF1 tumor suppressor gene at 17q11.2, resulting in heterozygous, loss-of-function mutations. Therefore, the production and/or function of its gene product, the protein neurofibromin, is subsequently impaired [14]. This protein interacts with several key cellular pathways and has multiple functions-the most germane of which is its role as a critical tumor suppressor gene via negative regulation of the RAS/RAF/MEK/ERK pathway [9,15]. Loss-of-function mutations in NF1, therefore, enable constitutive activation of this pathway, with resultant cell growth and proliferation. Patients with NF1 possess only a single functional copy of the NF1 gene (e.g., the "first hit"), with loss of the second copy acting as an oncogenic "second hit" and thereby allowing constitutive activation of this pathway [9]. Patients with NF1 are therefore at increased risk for multiple neoplastic processes-including MPNSTs [14]. A particular characteristic of NF1 is the extreme heterogeneity of its clinical manifestations, which may vary wildly even among members of the same kindred [16]. No specific alteration of the NF1 gene is specifically associated with the NF1 syndrome, and over 500 discrete mutations were identified [16]. This variability may be due both to the large size of the NF1 gene, which lends itself to a greater frequency of mutations, as well as the large number of possible means in which the function or amount of neurofibromin produced may be affected [16]. Genotype-phenotype correlations do exist for some specific mutations, but these constitute the minority of cases [17].

Though their presence is a hallmark of NF1, the presence of an MPNST does not ipso facto indicate a diagnosis of NF1. Although the most common neoplasms seen in patients with NF1 are benign neurofibromas, MPNSTs are the most common malignant neoplasm in this population, occurring in approximately $10 \%$ of patients with NF1 [16]. Conversely, as many as half of all MPNSTs are seen in patients with NF1 [1]. Although many MPNSTs are therefore sporadic, a diagnosis of NF1 is the primary known risk factor. Moreover, among those patients with NF1, a family history of NF1 and MPNST appears to be associated with an approximately three-fold greater risk of developing an MPNST in that patient [18]. Patients with whole-gene deletions of NF1, subcutaneous neurofibromas, or a larger number of plexiform neurofibromas are at particular risk of developing MPNST [19,20]. Compared to patients with sporadic MPNSTs, patients with NF1-associated MPNSTs also present them at an earlier age-typically in the second-tofourth decades of life [21]. Besides a diagnosis of NF1, the other primary known risk factor for MPNST development is radiation exposure, typically in the context of a secondary malignant neoplasm occurring following radiotherapy [22].

In most series, patients with either a diagnosis of NF1 or prior radiotherapy have shown a worse overall survival compared to those with sporadic MPNSTs-likely due to the greater propensity towards metastases and/or local invasion demonstrated by tumors in these patients [22-24]. However, the presence of NF1 itself does not directly appear to be the causative risk factor for these poorer outcomes-instead, patients with NF1 tend to have larger tumors, which are more challenging to fully resect [25]. The survival gap does appear to be narrowing, however, with patients with NF1-related MPNSTs faring better in studies performed more recently-though still not as well as those with sporadic MPNSTs [23]. 
Table 1. National Institutes of Health diagnostic criteria for neurofibromatosis type 1 [26].

In an individual who does not have a parent diagnosed with NF1, two or more are required to make a diagnosis of NF1:

- $\quad$ Pre-pubertal: $\geq 6$ café-au-lait macules $>5 \mathrm{~mm}$ in diameter

- Post-pubertal: $\geq 6$ café-au-lait macules $>15 \mathrm{~mm}$ in diameter

- Axillary or inguinal freckling

- $\quad \geq 2$ neurofibromas of any type, OR $\geq 1$ plexiform neurofibroma

- Optic pathway glioma

- $\quad \geq 2$ Lisch nodules, OR $\geq 2$ choroidal abnormalities

- Presence of a distinctive osseous lesion: sphenoid dysplasia OR anterolateral bowing of the tibia OR pseudarthrosis of a long bone

- $\quad$ Presence of a heterozygous pathogenic NF1 variant in apparently unaffected tissue (such as white blood cells), with a variant allele fraction of $\geq 50 \%$

If an individual has a parent who meets the above diagnostic criteria, a diagnosis of NF1 may be made in that individual if one or more of the above criteria are present.

\section{Characteristics of MPNSTs And Differentiation from Plexiform Neurofibromas}

\subsection{Clinical Features}

Patients with MPNSTs typically present with a history of a progressively expanding soft-tissue mass, which may or may not be painful [2]. In particular, the development of new neurological symptoms (e.g., hypoesthesia or dysesthesia), pain, and/or enlargement of an existing plexiform neurofibroma should raise suspicion for malignant transformation into an MPNST [26]. Symptoms are otherwise relatively non-specific and may be related to the disease site, e.g., neurologic compromise in the event of invasion into a nerve plexus or mass-effect due to tumor size/location [2].

\subsection{Radiology}

Imaging studies are necessary to delineate tumor extent and may also be of some use in differentiating MPNSTs versus plexiform neurofibromas. On MRI, features such as surrounding peritumoral edema, irregular and/or locally invasive margins, and intratumoral heterogeneity appear to be more indicative of MPNSTs (See Figure 1). However, the reported sensitivity and specificity of such findings are quite variable-ranging from less than $20 \%$ to over $90 \%$ [27-29]. Because MPNSTs exhibit higher metabolic activity than plexiform neurofibromas, 18F-FDG PET/CT may be useful in discriminating between these two entities (See Figure 2). Although some degree of overlap exists, standard uptake values (SUVs) of 1-4 tend to indicate benign tumors, while SUVs of 3-21 suggest the presence of MPNST [30-32]. Depending on the threshold used, sensitivity and specificity are greater than $90 \%$ and $70 \%$, respectively, for the detection of MPNSTs [30-32]. A tumor SUV of greater than 1.5-times that of normal hepatic tissue was also separately shown to be both a sensitive and specific indicator of MPNSTs [33]. 


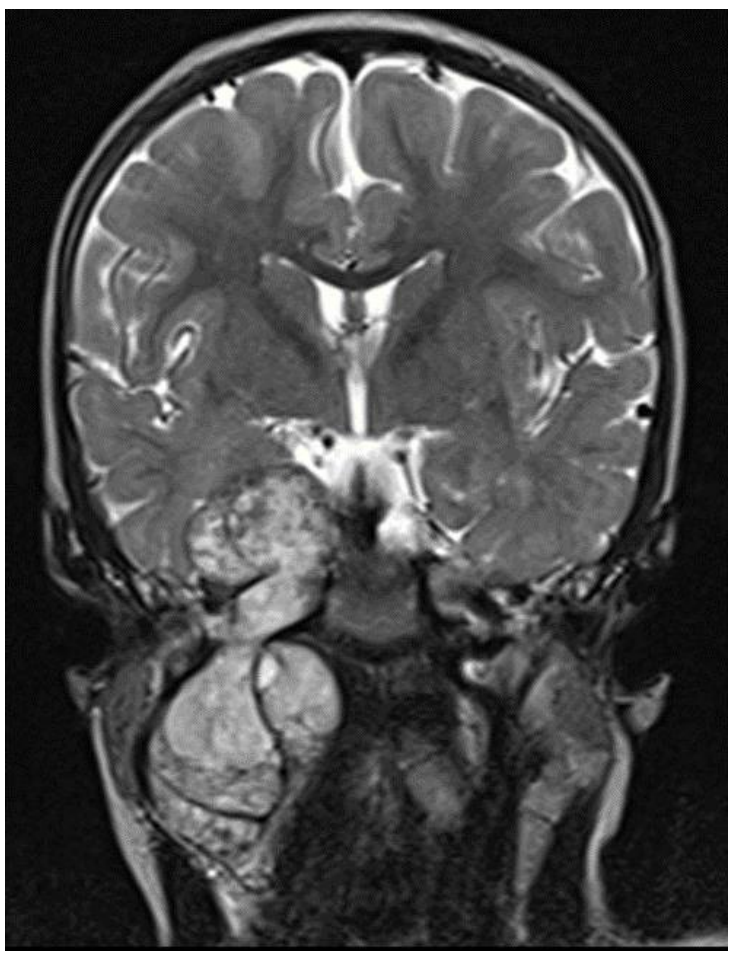

Figure 1. MRI T2 images, intratumor heterogeneity.

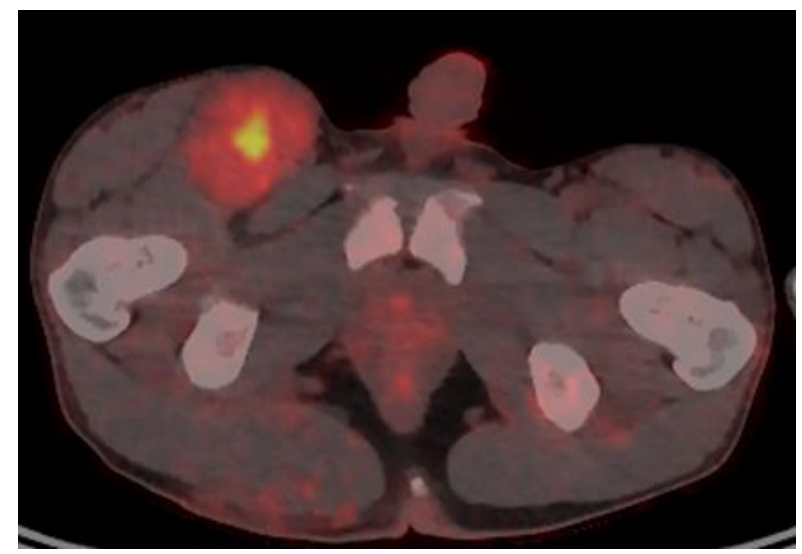

Figure 2. 18F-FDG PET/CT of a patient with NF1 and an MPNST of the right groin, with a maximal SUV of 7.

\subsection{Histopathology}

Although clinical and radiological features may be suggestive, definitive diagnosis of an MPNST requires histologic examination. This is complicated, however, by the absence of specific pathognomonic histopathological features, and diagnosis may be challenging [34]. A clear origin from either a peripheral nerve or a neurofibroma strongly aids in diagnosis [2]. Additionally, specific histologic features should be present, including fascicles with alternating, marble-like cellularity, palisade/rosette-like arrangements, and asymmetric spindle cells [2]. Based on the presence of high amounts of mitotic figures and necrosis, MPNSTs may be classified as high-grade or, conversely in the absence of necrosis/fewer mitotic figures, may be classified as low-grade (Figure 2).

Low-grade MPNSTs are sometimes difficult to histologically differentiate from benign plexiform neurofibromas [35]. Moreover, multiple patterns may exist in a single tumor, necessitating careful and complete examination [35]. A biopsy specimen may be insufficient to characterize the tumor adequately, and resection is preferred where possible [10]. 
However, in cases where the primary tumor is unresectable, percutaneous image-guided core-needle biopsy was shown to be highly accurate in differentiating benign versus malignant peripheral nerve sheath tumors [36] and may therefore be a reasonable option. The need to obtain adequate tissue for examination is counterbalanced by the potential for nerve injury. The risk of neurological deficits was reported as being as high as $60 \%$ in some series [37] and entirely absent in others [36]. This discrepancy likely arises secondary to the greater precision allowed by more recent diagnostic techniques, specifically, image guidance [36]. Immunohistochemical staining may include S100, Ki67, TP53, CD34, p16, and H3K27me3 (trimethylation at lysine 27 of histone H3) [35]. The interested reader is referred to an excellent review article on the histopathological diagnosis of nerve sheath tumors in general, including MPNSTs [38], see Figure 3.

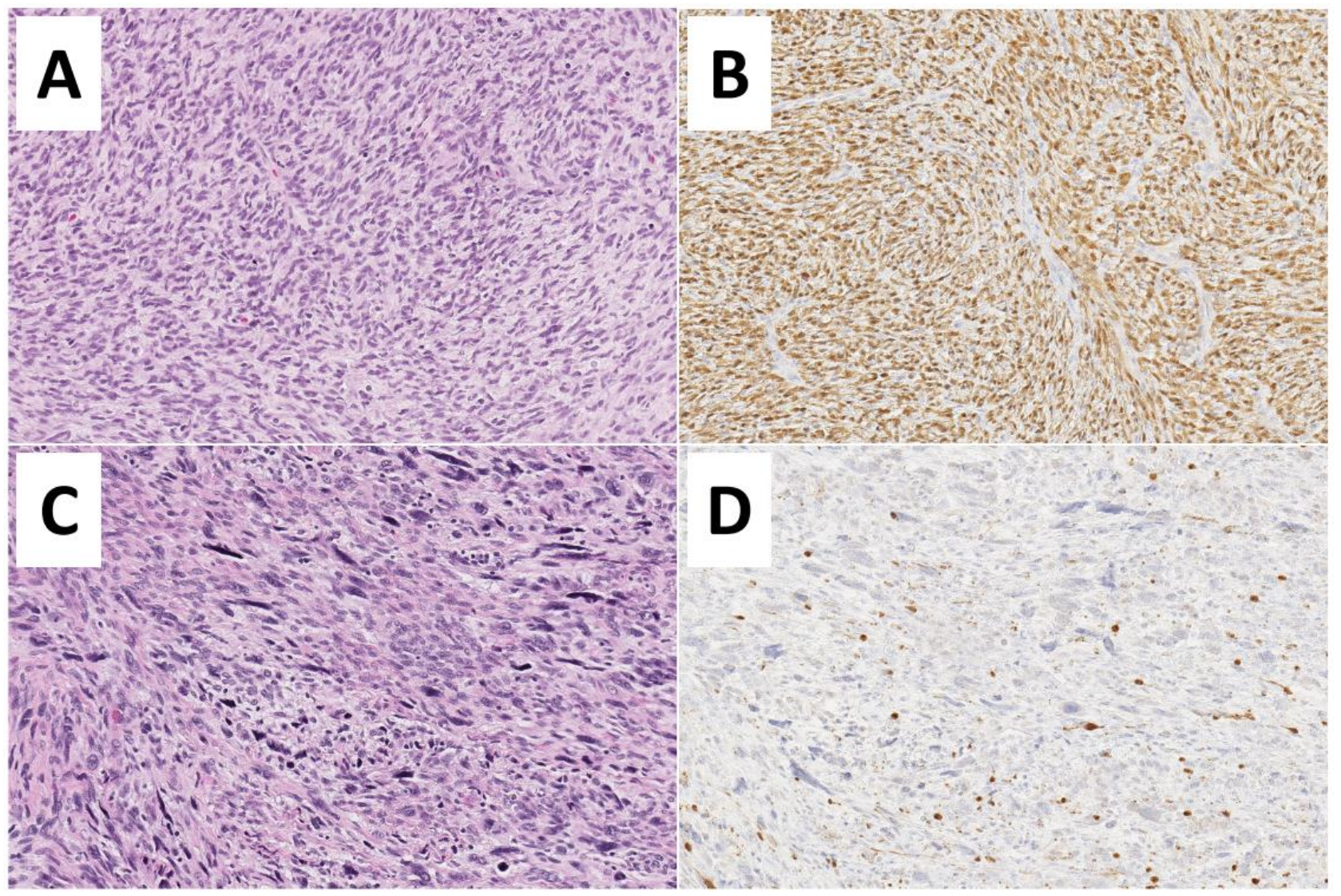

Figure 3. Histopathological features of Malignant Peripheral Nerve Sheath Tumors-MPNSTs. (A,B) Low-grade MPNST composed of a spindle cell proliferation with increased cellularity, mild cytological atypia, few mitoses ( 3 to 9 mitoses per 10 high-power fields), but no evidence of necrosis (Hematoxylin and Eosin, 200×). Diffuse immunoreactivity for S100-protein is noted (200×). (C,D) High-grade MPNST showing marked hypercellularity, nuclear pleomorphism, necrosis, and numerous mitoses (more than 10 mitoses per 10 high-power fields) (Hematoxylin and Eosin, 200×). Only focal S100protein positivity is observed.

\section{Staging and Risk Group Assignment of MPNST}

There is no disease-specific staging system for MPNST. Rather, MPNSTs (and NRSTS) were staged using two separate systems: The Intergroup Rhabdomyosarcoma Study Staging System [39,40] and the American Joint Committee on Cancer (AJCC) TNM staging system [41]. The former system was utilized for earlier trials, with the adoption of the AJCC staging system in more recent studies [42]. The recent Children's Oncology Group (COG) ARST0332 trial (which included MPNSTs) utilized the AJCC sixth edition staging system, which was current at the time of study inception. The eighth edition of these guidelines 
was recently published [43]. Briefly, the AJCC staging system utilizes the size, depth, and invasiveness of the tumor $(\mathrm{T})$, the presence/absence of lymph node involvement $(\mathrm{N})$, and the presence/absence of distant metastasis (M) to assign a stage from 1 to 4 , some of which include multiple sub-stages. In addition, tumor histologic grade is a key consideration-and is included in both the eighth edition of the AJCC staging system and ARST0332 risk group assignments [42,43]. Both the Federation Nationale des Centres de Lutte Contre le Cancer (FNCLCC) [44] and Pediatric Oncology Group (POG) [45] assign tumors to either a low-grade (POG 1 or 2, FNCLCC 1) or high-grade (POG 3, FNCLCC 1 or 2), on the basis of tumor differentiation, mitosis, and necrosis. Both systems are prognostic, with high-grade predicting a poorer outcome [42,46].

Modern treatment strategies for NRSTS in general (including MPNSTs) are therefore ultimately based on that tumor's local characteristics, nodal involvement, metastatic spread, and histologic grade-as well as the extent of surgery/margin status [42]. From these, a stage and risk group may be assigned, which informs subsequent management. The COG ARST0332 trial assigned patients to one of three risk groups. Low-risk tumors were defined as: non-metastatic, low-grade, grossly resected tumors irrespective of margin status, OR non-metastatic, high-grade, grossly resected tumors regardless of margin status and $\leq 5 \mathrm{~cm}$. Intermediate-risk tumors were defined as non-metastatic, high-grade, grossly resected tumors irrespective of margin status and $>5 \mathrm{~cm}$, OR non-metastatic, unresected tumor of any size or grade. Finally, high-risk tumors were defined as those with metastases to lymph nodes, distant sites, or both [42]. Based on risk group assignment, treatment groups were assigned; these are outlined below. Therefore, it is reasonable to stage MPNSTs using this strategy, as the ARST0332 clinical trial will likely inform future management and studies of NRSTs, including MPNSTs.

\section{Management of MPNSTs}

As a group, NRSTS may be crudely divided into those which are more sensitive to chemotherapy (e.g., synovial sarcoma [47]) and those which are less sensitive (e.g., clear cell sarcoma [48]). In either case, the most critical component of management is surgical resection-particularly in the latter group. MPNSTs are poorly responsive to chemotherapy, at least partially due to their slow growth rate. Their primary management is therefore surgical in nature, with non-surgical modalities playing a supportive yet essential role, particularly in metastatic, invasive, or widespread disease.

Patients with MPNSTs were eligible for inclusion in the recently reported COG ARST0332 trial [42]. Fifty-eight patients with MPNSTs were included, comprising 11\% of the total study population $(\mathrm{N}=529$, and constituting the second-largest cohort after those with synovial sarcoma $(25 \% ; \mathrm{N}=128)$. Following risk group assignment (as outlined above), patients were enrolled into one of four treatment groups: surgery alone (Arm A), surgery plus adjuvant radiotherapy (Arm B), surgery plus adjuvant chemotherapy and radiotherapy (Arm C), or neoadjuvant chemotherapy and radiotherapy, surgery, and then adjuvant chemotherapy and radiation therapy (Arm D). Both Arm C and Arm D utilized combined doxorubicin plus ifosfamide chemotherapy. Patients with MPNSTs were represented in each of the four treatment groups and were assigned as follows: 7 patients on Arm A, 2 on Arm B, and 19 patients on Arm C. Most patients with MPNSTs were enrolled on Arm D $(n=32)$. Although MPNST-specific results are not available at this time, general outcomes are compared favorably to prior studies. At a median follow-up time of 6.5 years, that study's 5-year overall survival (OS) and event-free survival (EFS) were as follows-low risk: $96.2 \%$ and $88.9 \%$, respectively. Intermediate risk: $79.2 \%$ and $65.0 \%$, respectively. High risk: $35.5 \%$ and $21.2 \%$, respectively [42].

Given MPNSTs' locally aggressive nature and tendency to metastasize, multidisciplinary, multi-modality management is frequently a feature of many patients' treatment courses. It is, therefore, somewhat artificial to discuss each in isolation. Additionally, patients with more advanced disease are more likely to both receive more intensive/multi- 
modality therapy-and to have worse outcomes. We have, however, sought to provide an overview of unique, modality-specific considerations below.

\subsection{Surgical Management and Surgery-Specific Considerations}

Resectability is strongly related to outcomes, and survival depends upon wide resection [49,50]. Wide local resection involving $\mathrm{R} 0$ resection with a least $2 \mathrm{~cm}$ margin in all directions is a major determinant of outcomes in patients with soft tissue sarcomas in general [51,52]. However, in patients with MPNST, R0 resection is not always possible due to the nature and biology of these tumors.

MPNST can develop anywhere in the body but occur mainly at the location of major nerve plexuses/roots. Extremities are most commonly involved, followed by the trunk, and head, and neck. MPNSTs of the extremities have superior outcomes compared to other disease sites, most likely secondary to an enhanced ability to achieve R0 resections and improved tumor control [49]. The most common extremity location for MPNST is the brachial plexus, with total resection being the goal. Here, and in other areas, R0 resection may result in unacceptable morbidity. Historically, treatment usually included local resection to confirm the diagnosis. This was followed by amputation for more proximal involvement of the associated plexus-resulting in severe neurological deficits. If the relevant local vasculature was also involved, the resulting resection would also compromise local blood flow and potentially result in limb ischemia/necrosis. If an en bloc resection of a major nerve bundle were performed, such as the brachial plexus, sciatic nerve, or spinal roots in the trunk, this would also create circumstances leading to the development of pressure sores and necessitating secondary amputations.

Conversely, current literature supports limb-sparing procedures (LSP) $[49,50,52]$. LSPs allow for retention of the afflicted limb in the context of localized disease $[49,53]$. Limb sacrifice (e.g., amputation) therefore occurs in approximately 5-10\% of patients for whom wide excision is not feasible-and who can tolerate such surgery and do not have metastatic disease $[49,53]$. Those who do undergo LSP also undergo local soft tissue irradiation with implanted rods supplemented by external beam radiation. When contemplating whether to perform limb-sparing versus limb-sacrifice procedures, it is important to consider that for MPNSTs at the level of the plexus, amputation offers superior survival as compared to local resection if an $\mathrm{R} 0$ resection is not possible [49,54].

In patients with head and neck MPNSTs, R0 resection is extremely difficult to achieve secondary to local anatomy and critical structures. This likely contributes to the poorer outcome seen in these patients. Wide local resection and R0 margins remain the goal, however. If not possible, resection of the tumor without sacrificing major neurovascular structures is appropriate, followed by adjuvant therapy [52].

Intraoperatively, the surgeon may appreciate a firm, solid mass. Locally advanced disease with invasion to the adjacent tissue or vasculature is common. There may also be disruption of anatomical planes with edema. The surgeon may perform intraoperative highresolution ultrasound, which may reveal an irregular, isoechoic, or hypo to hyperechoic structure with solid and cystic structures. On ultrasound and on gross pathology, features of necrosis may be present [55].

Some literature would suggest that patients with localized soft tissue sarcomas may benefit from undergoing re-resection if there was an apparent macroscopic tumor left in the tumor bed. This approach decreases local tumor burden in anticipation of or following local radiotherapy [52,56]. Given the rarity of these tumors, their aggressive nature, and the relative lack of literature, further studies are needed to fully understand the optimal surgical management of these tumors.

\subsection{Traditional Chemotherapy}

Prior to the COG trial ARST0332, a small number of studies have evaluated MPNST responses to traditional chemotherapeutic agents-typically mono-or-combination therapy with ifosfamide and/or anthracyclines (doxorubicin/epirubicin), sometimes in combina- 
tion with etoposide. These studies assessed both neoadjuvant [57-59] and adjuvant [60-62] approaches. Because of the relative rarity of NRSTS of all subtypes, randomized controlled clinical trials are lacking, and it is difficult to draw definitive conclusions from the existent studies. Although considerable inter-study heterogeneity exists, systemic chemotherapy has generally been administered in the setting of locally invasive, large (e.g., $>5 \mathrm{~cm}$ ), deeply located, and/or metastatic disease. Unsurprisingly response rates are disappointing, generally clustering at approximately $50 \%$, with the vast majority of these being either stable disease or partial response [63].

Patients with MPNST have also occasionally been included in studies of other softtissue sarcomas. In those studies, they have generally been treated as-per rhabdomyosarcoma protocols-with primary excision where possible, or neoadjuvant chemotherapy if not, and adjuvant chemo/radiotherapy for those at risk of local reoccurrence [64]. Agents administered are typical of rhabdomyosarcoma therapy and overall response rates for patients requiring chemotherapy are generally also around the 50\% mark-though regimens utilizing ifosfamide achieved markedly higher response rates [64]. However, any interpretation of such studies must be under the caveat that staging/grading of MPNSTs is not consistent across trials, which complicates comparison.

\subsection{Targeted and Novel Agents}

Partially because MPNSTs are resistant to traditional chemotherapeutic agents, the use of targeted therapies is appealing. These strategies are based upon the improving understanding of the molecular basis of this neoplasm. As outlined above, MPNSTs possess multiple targetable pathways $[13,65]$. Of these, the most implicated appears to be the Ras/Raf/MEK/ERK pathway [65]. This pathway is also relatively well understood and one against which multiple inhibitors exist. A complete response to MEK inhibition was reported [66], and within the context of MPNST, clinical trials of Ras/Raf/MEK/ERK pathway inhibition are ongoing [67]. This approach has also seen relatively well-documented success in other NF1-associated tumors, including low-grade gliomas (LGGs) and plexiform neurofibromas [15,68], with formal clinical trial assessment underway [69-71]. As is the case with MPNSTs, these tumors may be poorly responsive or refractory to "traditional" chemotherapeutic management. The interested reader is referred to an excellent recent review article on potential novel pharmacologic approaches to the management of peripheral nerve sheath tumors-including existent clinical trials [63]. It should be reiterated that such practices remain experimental, and patients should be enrolled in clinical trials to better understand the efficacy of these therapies.

Moreover, essentially all-such trials require these patients' MPNSTS to be partially or unresectable, inoperable, metastatic, or otherwise not amenable to definitive surgical management. Finally, the optimal strategies for integrating surgical resection with targeted therapies remain to be developed. We speculate, however, that neoadjuvant pharmacological therapy could best be used to render unresectable tumors operable-essentially recapitulating the successful strategies utilized in more chemo-sensitive NRSTS, but with pathway-specific agents.

The field of pediatric oncology is rife with instances of rationally designed, targeted therapies achieving breakthroughs and becoming standard of care/frontline therapy-such as was achieved via the use of the anti-GD2 antibody dinutuximab for patients with high-risk neuroblastoma [72]. However, it is at least as common, if not more so, for mechanistically promising therapies to fail upon clinical translation $[73,74]$. Therefore, at the present time, complete surgical resection is the only therapy that provides a durable cure for MPNSTs. Within the next decade, however, it would not be surprising to witness the integration of standardized pharmacological neoadjuvant or targeted adjuvant therapies, with definitive surgical management-not only for tumors that are metastatic or non-resectable but as a matter of course to minimize pre-operative disease burden. 


\subsection{Radiation Therapy}

Given (a) the high proportion of patients with MPNST who also have NF1 and (b) the heightened radiation sensitivity of patients with NF1, radiation therapy should be used with caution in the context of MPNSTs. Radiation itself is a well-documented risk factor for MPNST (and other secondary malignancies) in patients with NF1 [75]. The median cumulative radiation doses needed for therapeutic efficacy are also quite high-often well in excess of 50 Gray (Gy) [63,76]. The literature generally suggests that radiotherapy is most useful in patients with large (e.g., $>5 \mathrm{~cm}$ ), high-grade tumors, and/or those with positive margins at resection $[63,76,77]$. It appears that the risk of local recurrence is reduced, but with an unclear benefit upon actual survival [76,77]. Moreover, radiotherapy timing (preoperative versus post-operative) does not appear to have a statistical effect on the ability to achieve local control [78,79]. However, reasonable theoretical arguments can be made for either approach. The recent COG study ARST0332 included arms with both approaches, based on risk group assignment [42]. Patients who had undergone initial gross total resection subsequently underwent adjuvant radiotherapy (Arm B) or chemo-radiotherapy (Arm C) using 55.8 Gy (31 fractions of $1.8 \mathrm{~Gy}$ ). Conversely, those with unresected or metastatic disease received both neoadjuvant and adjuvant chemo-radiotherapy (Arm D). This approach used $45 \mathrm{~Gy}$ ( 25 fractions of $1.8 \mathrm{~Gy}$ ) neoadjuvant radiotherapy to the primary site, followed by resection and adjuvant radiotherapy with the dose determined by the success of resection-10.8 Gy (6 fractions of $1.8 \mathrm{~Gy}$ ) for microscopic residual disease R1 (cumulative dose 55. $8 \mathrm{~Gy}$ ) or $19.8 \mathrm{~Gy}$ (11 fractions of $1.8 \mathrm{~Gy}$ ) for gross residual disease/no resection (cumulative dose $64.8 \mathrm{~Gy}$ ) [42].

\section{Conclusions}

The MPNST treatment philosophy can therefore be summarized as thus: maximal surgical resection, potentially in combination with neoadjuvant chemotherapy or radiotherapy to render an initially inoperable tumor operable, followed by adjuvant chemotherapy or radiotherapy when the margins of resection are positive or metastatic disease exists.

Author Contributions: Conceptualization, S.W.E.K., T.E.K., A.H.A. and A.J.M.; Writing-Original Draft Preparation, S.W.E.K., T.E.K., A.H.A. and A.J.M.; Writing-Review and Editing-S.W.E.K., T.E.K., A.H.A., T.S. and A.J.M.; Supervision-A.H.A. All authors have read and agreed to the published version of the manuscript.

Funding: This research was funded by the American Lebanese Associated Charities (ALSAC)/St. Jude Children's Research Hospital.

Institutional Review Board Statement: Not applicable.

Informed Consent Statement: Not applicable.

Data Availability Statement: Not applicable, the study did not report any data.

Conflicts of Interest: The authors declare no conflict of interest. The funders had no role in the design of the study; in the collection, analyses, or interpretation of data; in the writing of the manuscript, or in the decision to publish the results.

\section{References}

1. Amirian, E.S.; Goodman, J.C.; New, P.; Scheurer, M.E. Pediatric and Adult Malignant Peripheral Nerve Sheath Tumors: An Analysis of Data from the Surveillance, Epidemiology, and End Results Program. J. Neuro-Oncol. 2014, 116, 609-616. [CrossRef]

2. Ferrari, A.; Bisogno, G.; Carli, M. Management of Childhood Malignant Peripheral Nerve Sheath Tumor. Pediatr. Drugs 2007, 9 , 239-248. [CrossRef]

3. Childhood Soft Tissue Sarcoma Treatment $\left(\mathrm{PDQ}^{\circledR}\right)-$ Health Professional Version-National Cancer Institute. Available online: https://www.cancer.gov/types/soft-tissue-sarcoma/hp/child-soft-tissue-treatment-pdq (accessed on 29 July 2021).

4. WHO Classification of Tumours Editorial Board. Soft Tissue and Bone Tumours; International Agency for Research on Cancer (IARC): Lyon, France, 2020; ISBN 978-92-832-4502-5.

5. Fletcher, C.D.M.; Bridge, J.A.; Hogendoorn, P.C.W.; Mertens, F. WHO Classification of Tumours of Soft Tissue and Bone; International Agency for Research on Cancer (IARC): Lyon, France, 2020; ISBN 9789283224341. 
6. Kleinerman, R.A.; Tucker, M.A.; Abramson, D.H.; Seddon, J.M.; Tarone, R.E.; Fraumeni, J.F.J. Risk of Soft Tissue Sarcomas by Individual Subtype in Survivors of Hereditary Retinoblastoma. J. Natl. Cancer Inst. 2007, 99, 24-31. [CrossRef] [PubMed]

7. Del Baldo, G.; Carta, R.; Alessi, I.; Merli, P.; Agolini, E.; Rinelli, M.; Boccuto, L.; Milano, G.M.; Serra, A.; Carai, A.; et al. Rhabdoid Tumor Predisposition Syndrome: From Clinical Suspicion to General Management. Front. Oncol. 2021, 11, 586288. [CrossRef]

8. Albert, C.M.; Davis, J.L.; Federman, N.; Casanova, M.; Laetsch, T.W. TRK Fusion Cancers in Children: A Clinical Review and Recommendations for Screening. J. Clin. Oncol. 2018, 37, 513-524. [CrossRef] [PubMed]

9. Bergoug, M.; Doudeau, M.; Godin, F.; Mosrin, C.; Vallée, B.; Bénédetti, H. Neurofibromin Structure, Functions and Regulation. Cells 2020, 9, 2365. [CrossRef] [PubMed]

10. Prudner, B.C.; Ball, T.; Rathore, R.; Hirbe, A.C. Diagnosis and Management of Malignant Peripheral Nerve Sheath Tumors: Current Practice and Future Perspectives. Neuro-Oncol. Adv. 2020, 2, i40-i49. [CrossRef] [PubMed]

11. Zhu, Y.; Ghosh, P.; Charnay, P.; Burns, D.K.; Parada, L.F. Neurofibromas in NF1: Schwann Cell Origin and Role of Tumor Environment. Science 2002, 296, 920-922. [CrossRef]

12. De Raedt, T.; Beert, E.; Pasmant, E.; Luscan, A.; Brems, H.; Ortonne, N.; Helin, K.; Hornick, J.L.; Mautner, V.; Kehrer-Sawatzki, H.; et al. PRC2 Loss Amplifies Ras-Driven Transcription and Confers Sensitivity to BRD4-Based Therapies. Nature 2014, 514, 247-251. [CrossRef] [PubMed]

13. Röhrich, M.; Koelsche, C.; Schrimpf, D.; Capper, D.; Sahm, F.; Kratz, A.; Reuss, J.; Hovestadt, V.; Jones, D.T.W.; Bewerunge-Hudler M.; et al. Methylation-Based Classification of Benign and Malignant Peripheral Nerve Sheath Tumors. Acta Neuropathol. 2016, 131, 877-887. [CrossRef]

14. Reynolds, R.M.; Browning, G.G.P.; Nawroz, I.; Campbell, I.W. Von Recklinghausen's Neurofibromatosis: Neurofibromatosis Type 1. Lancet 2003, 361, 1552-1554. [CrossRef]

15. Knight, T.; Shatara, M.; Carvalho, L.; Altinok, D.; Poulik, J.; Wang, Z.J. Dramatic response to trametinib in a male child with neurofibromatosis type 1 and refractory astrocytoma. Pediatr. Blood Cancer 2019, 66, e27474. [CrossRef] [PubMed]

16. Friedman, J.M. Neurofibromatosis 1. In GeneReviews ${ }^{\circledR}$; Adam, M.P., Ardinger, H.H., Pagon, R.A., Wallace, S.E., Bean, L.J., Mirzaa, G., Amemiya, A., Eds.; University of Washington Seattle: Seattle, WA, USA, 1993.

17. Shofty, B.; Constantini, S.; Ben-Shachar, S. Advances in Molecular Diagnosis of Neurofibromatosis Type 1. Semin. Pediatr. Neurol. 2015, 22, 234-239. [CrossRef] [PubMed]

18. Malbari, F.; Spira, M.; Knight, P.B.; Zhu, C.; Roth, M.; Gill, J.; Abbott, R.; Levy, A.S. Malignant Peripheral Nerve Sheath Tumors in Neurofibromatosis: Impact of Family History. J. Pediatr. Hematol. Oncol. 2018, 40, e359-e363. [CrossRef]

19. Kluwe, L.; Friedrich, R.E.; Peiper, M.; Friedman, J.; Mautner, V.-F. Constitutional NF1 Mutations in Neurofibromatosis 1 Patients with Malignant Peripheral Nerve Sheath Tumors. Hum. Mutat. 2003, 22, 420. [CrossRef] [PubMed]

20. Nguyen, R.; Jett, K.; Harris, G.J.; Cai, W.; Friedman, J.M.; Mautner, V.-F. Benign Whole Body Tumor Volume Is a Risk Factor for Malignant Peripheral Nerve Sheath Tumors in Neurofibromatosis Type 1. J. Neuro-Oncol. 2014, 116, 307-313. [CrossRef] [PubMed]

21. Valentin, T.; Le Cesne, A.; Coquard, R.I.; Italiano, A.; Decanter, G.; Bompas, E.; Isambert, N.; Thariat, J.; Linassier, C.; Bertucci, F.; et al. Management and Prognosis of Malignant Peripheral Nerve Sheath Tumors: The Experience of the French Sarcoma Group (GSF-GETO). Eur. J. Cancer 2016, 56, 77-84. [CrossRef]

22. Miao, R.; Wang, H.; Jacobson, A.; Lietz, A.P.; Choy, E.; Raskin, K.A.; Schwab, J.H.; Deshpande, V.; Nielsen, G.P.; DeLaney, T.F.; et al. Radiation-Induced and Neurofibromatosis-Associated Malignant Peripheral Nerve Sheath Tumors (MPNST) Have Worse Outcomes than Sporadic MPNST. Radiother. Oncol. 2019, 137, 61-70. [CrossRef] [PubMed]

23. Kolberg, M.; Høland, M.; Ågesen, T.H.; Brekke, H.R.; Liestøl, K.; Hall, K.S.; Mertens, F.; Picci, P.; Smeland, S.; Lothe, R.A Survival Meta-Analyses for $>1800$ Malignant Peripheral Nerve Sheath Tumor Patients with and without Neurofibromatosis Type 1. Neuro-Oncology 2013, 15, 135-147. [CrossRef] [PubMed]

24. Cai, Z.; Tang, X.; Liang, H.; Yang, R.; Yan, T.; Guo, W. Prognosis and Risk Factors for Malignant Peripheral Nerve Sheath Tumor: A Systematic Review and Meta-Analysis. World J. Surg. Oncol. 2020, 18, 257. [CrossRef]

25. Anghileri, M.; Miceli, R.; Fiore, M.; Mariani, L.; Ferrari, A.; Mussi, C.; Lozza, L.; Collini, P.; Olmi, P.; Casali, P.G.; et al. Malignant Peripheral Nerve Sheath Tumors: Prognostic Factors and Survival in a Series of Patients Treated at a Single Institution. Cancer 2006, 107, 1065-1074. [CrossRef]

26. Legius, E.; Messiaen, L.; Wolkenstein, P.; Pancza, P.; Avery, R.A.; Berman, Y.; Blakeley, J.; Babovic-Vuksanovic, D.; Soares Cunha, K.; Ferner, R.; et al. Revised diagnostic criteria for neurofibromatosis type 1 and Legius syndrome: An international consensus recommendation. Genet. Med. 2021, 23, 1506-1513. [CrossRef]

27. Valeyrie-Allanore, L.; Ismaili, N.; Bastuji-Garin, S.; Zeller, J.; Wechsler, J.; Revuz, J.; Wolkenstein, P. Symptoms Associated with Malignancy of Peripheral Nerve Sheath Tumours: A Retrospective Study of 69 Patients with Neurofibromatosis 1. Br. J. Dermatol. 2005, 153, 79-82. [CrossRef]

28. Demehri, S.; Belzberg, A.; Blakeley, J.; Fayad, L.M. Conventional and Functional MR Imaging of Peripheral Nerve Sheath Tumors: Initial Experience. AJNR Am. J. Neuroradiol. 2014, 35, 1615-1620. [CrossRef]

29. Matsumine, A.; Kusuzaki, K.; Nakamura, T.; Nakazora, S.; Niimi, R.; Matsubara, T.; Uchida, K.; Murata, T.; Kudawara, I.; Ueda, T.; et al. Differentiation between Neurofibromas and Malignant Peripheral Nerve Sheath Tumors in Neurofibromatosis 1 Evaluated by MRI. J. Cancer Res. Clin. Oncol. 2009, 135, 891-900. [CrossRef] 
30. Well, L.; Salamon, J.; Kaul, M.G.; Farschtschi, S.; Herrmann, J.; Geier, K.I.; Hagel, C.; Bockhorn, M.; Bannas, P.; Adam, G.; et al. Differentiation of Peripheral Nerve Sheath Tumors in Patients with Neurofibromatosis Type 1 Using Diffusion-Weighted Magnetic Resonance Imaging. Neuro-Oncology 2019, 21, 508-516. [CrossRef]

31. Azizi, A.A.; Slavc, I.; Theisen, B.E.; Rausch, I.; Weber, M.; Happak, W.; Aszmann, O.; Hojreh, A.; Peyrl, A.; Amann, G.; et al. Monitoring of Plexiform Neurofibroma in Children and Adolescents with Neurofibromatosis Type 1 by [(18) F]FDG-PET Imaging. Is It of Value in Asymptomatic Patients? Pediatr. Blood Cancer 2018, 65, e26733. [CrossRef] [PubMed]

32. Berzaczy, D.; Mayerhoefer, M.E.; Azizi, A.A.; Haug, A.R.; Senn, D.; Beitzke, D.; Weber, M.; Traub-Weidinger, T. Does Elevated Glucose Metabolism Correlate with Higher Cell Density in Neurofibromatosis Type 1 Associated Peripheral Nerve Sheath Tumors? PLoS ONE 2017, 12, e0189093. [CrossRef]

33. Assadi, M.; Velez, E.; Najafi, M.H.; Matcuk, G.; Gholamrezanezhad, A. PET Imaging of Peripheral Nerve Tumors. PET Clin. 2019, 14, 81-89. [CrossRef]

34. Combemale, P.; Valeyrie-Allanore, L.; Giammarile, F.; Pinson, S.; Guillot, B.; Goulart, D.M.; Wolkenstein, P.; Blay, J.Y.; Mognetti, T. Utility of 18F-FDG PET with a Semi-Quantitative Index in the Detection of Sarcomatous Transformation in Patients with Neurofibromatosis Type 1. PLoS ONE 2014, 9, e85954. [CrossRef]

35. Le Guellec, S.; Decouvelaere, A.-V.; Filleron, T.; Valo, I.; Charon-Barra, C.; Robin, Y.-M.; Terrier, P.; Chevreau, C.; Coindre, J.-M. Malignant Peripheral Nerve Sheath Tumor Is a Challenging Diagnosis: A Systematic Pathology Review, Immunohistochemistry, and Molecular Analysis in 160 Patients from the French Sarcoma Group Database. Am. J. Surg. Pathol. 2016, 40, 896-908. [CrossRef]

36. Kim, A.; Stewart, D.R.; Reilly, K.M.; Viskochil, D.; Miettinen, M.M.; Widemann, B.C. Malignant Peripheral Nerve Sheath Tumors State of the Science: Leveraging Clinical and Biological Insights into Effective Therapies. Sarcoma 2017, 2017, 7429697. [CrossRef] [PubMed]

37. Graham, D.S.; Russell, T.A.; Eckardt, M.A.; Motamedi, K.; Seeger, L.L.; Singh, A.S.; Bernthal, N.M.; Kalbasi, A.; Dry, S.M.; Nelson, S.D.; et al. Oncologic Accuracy of Image-Guided Percutaneous Core-Needle Biopsy of Peripheral Nerve Sheath Tumors at a High-Volume Sarcoma Center. Am. J. Clin. Oncol. 2019, 42, 739-743. [CrossRef]

38. Perez-Roman, R.J.; Shelby Burks, S.; Debs, L.; Cajigas, I.; Levi, A.D. The Risk of Peripheral Nerve Tumor Biopsy in Suspected Benign Etiologies. Neurosurgery 2020, 86, E326-E332. [CrossRef]

39. Rodriguez, F.J.; Folpe, A.L.; Giannini, C.; Perry, A. Pathology of Peripheral Nerve Sheath Tumors: Diagnostic Overview and Update on Selected Diagnostic Problems. Acta Neuropathol. 2012, 123, 295-319. [CrossRef]

40. Pratt, C.B.; Maurer, H.M.; Gieser, P.; Salzberg, A.; Rao, B.N.; Parham, D.; Thomas, P.R.; Marcus, R.B.; Cantor, A.; Pick, T.; et al. Treatment of Unresectable or Metastatic Pediatric Soft Tissue Sarcomas with Surgery, Irradiation, and Chemotherapy: A Pediatric Oncology Group Study. Med. Pediatr. Oncol. 1998, 30, 201-209. [CrossRef]

41. Pratt, C.B.; Pappo, A.S.; Gieser, P.; Jenkins, J.J.; Salzbergdagger, A.; Neff, J.; Rao, B.; Green, D.; Thomas, P.; Marcus, R.; et al. Role of Adjuvant Chemotherapy in the Treatment of Surgically Resected Pediatric Nonrhabdomyosarcomatous Soft Tissue Sarcomas: A Pediatric Oncology Group Study. J. Clin. Oncol. Off. J. Am. Soc. Clin. Oncol. 1999, 17, 1219. [CrossRef]

42. Purposes and Principles of Staging. In AJCC Cancer Staging Manual; Greene, F.L.; Page, D.L.; Fleming, I.D.; Fritz, A.G.; Balch, C.M.; Haller, D.G.; Morrow, M. (Eds.) Springer: New York, NY, USA, 2002; pp. 3-8. ISBN 978-1-4757-3656-4.

43. Spunt, S.L.; Million, L.; Chi, Y.-Y.; Anderson, J.; Tian, J.; Hibbitts, E.; Coffin, C.; McCarville, M.B.; Randall, R.L.; Parham, D.M.; et al. A Risk-Based Treatment Strategy for Non-Rhabdomyosarcoma Soft-Tissue Sarcomas in Patients Younger than 30 Years (ARST0332): A Children's Oncology Group Prospective Study. Lancet Oncol. 2020, 21, 145-161. [CrossRef]

44. AJCC Cancer Staging Manual, 8th ed.; Amin, M.B.; Edge, S.; Greene, F.; Byrd, D.R.; Brookland, R.K.; Washington, M.K.; Gershenwald, J.E.; Compton, C.C.; Hess, K.R.; Sullivan, D.C. (Eds.) Springer International Publishing: Berlin/Heidelberg, Germany, 2017; ISBN 978-3-319-40617-6

45. Coindre, J.M.; Terrier, P.; Guillou, L.; Le Doussal, V.; Collin, F.; Ranchère, D.; Sastre, X.; Vilain, M.O.; Bonichon, F.; N’Guyen Bui, B. Predictive Value of Grade for Metastasis Development in the Main Histologic Types of Adult Soft Tissue Sarcomas: A Study of 1240 Patients from the French Federation of Cancer Centers Sarcoma Group. Cancer 2001, 91, 1914-1926. [CrossRef]

46. Parham, D.M.; Webber, B.L.; Jenkins, J.J., 3rd; Cantor, A.B.; Maurer, H.M. Nonrhabdomyosarcomatous Soft Tissue Sarcomas of Childhood: Formulation of a Simplified System for Grading. Mod. Pathol. Off. J. United States Can. Acad. Pathol. Inc. 1995, 8, 705-710.

47. Khoury, J.D.; Coffin, C.M.; Spunt, S.L.; Anderson, J.R.; Meyer, W.H.; Parham, D.M. Grading of Nonrhabdomyosarcoma Soft Tissue Sarcoma in Children and Adolescents: A Comparison of Parameters Used for the Fédération Nationale des Centers de Lutte Contre le Cancer and Pediatric Oncology Group Systems. Cancer 2010, 116, 2266-2274. [CrossRef]

48. Ferrari, A.; Gronchi, A.; Casanova, M.; Meazza, C.; Gandola, L.; Collini, P.; Lozza, L.; Bertulli, R.; Olmi, P.; Casali, P.G. Synovial Sarcoma: A Retrospective Analysis of 271 Patients of All Ages Treated at a Single Institution. Cancer 2004, 101, 627-634. [CrossRef]

49. Ferrari, A.; Casanova, M.; Bisogno, G.; Mattke, A.; Meazza, C.; Gandola, L.; Sotti, G.; Cecchetto, G.; Harms, D.; Koscielniak, E.; et al. Clear Cell Sarcoma of Tendons and Aponeuroses in Pediatric Patients: A Report from the Italian and German Soft Tissue Sarcoma Cooperative Group. Cancer 2002, 94, 3269-3276. [CrossRef]

50. Gachiani, J.; Kim, D.; Nelson, A.; Kline, D. Surgical Management of Malignant Peripheral Nerve Sheath Tumors. Neurosurg. Focus 2007, 22, E13. [CrossRef] 
51. Baehring, J.M.; Betensky, R.A.; Batchelor, T.T. Malignant Peripheral Nerve Sheath Tumor: The Clinical Spectrum and Outcome of Treatment. Neurology 2003, 61, 696-698. [CrossRef]

52. Angelov, L.; Davis, A.; O'Sullivan, B.; Bell, R.; Guha, A. Neurogenic Sarcomas: Experience at the University of Toronto. Neurosurgery 1998, 43, 56-64, discussion 64-65. [CrossRef] [PubMed]

53. Zagars, G.K.; Ballo, M.T.; Pisters, P.W.T.; Pollock, R.E.; Patel, S.R.; Benjamin, R.S. Surgical Margins and Reresection in the Management of Patients with Soft Tissue Sarcoma Using Conservative Surgery and Radiation Therapy. Cancer 2003, 97, 2544-2553. [CrossRef]

54. Frustaci, S.; Gherlinzoni, F.; De Paoli, A.; Bonetti, M.; Azzarelli, A.; Comandone, A.; Olmi, P.; Buonadonna, A.; Pignatti, G.; Barbieri, E.; et al. Adjuvant Chemotherapy for Adult Soft Tissue Sarcomas of the Extremities and Girdles: Results of the Italian Randomized Cooperative Trial. J. Clin. Oncol. 2001, 19, 1238-1247. [CrossRef]

55. Kar, M.; Deo, S.V.S.; Shukla, N.K.; Malik, A.; DattaGupta, S.; Mohanti, B.K.; Thulkar, S. Malignant Peripheral Nerve Sheath Tumors (MPNST)-Clinicopathological Study and Treatment Outcome of Twenty-Four Cases. World J. Surg. Oncol. $2006,4,55$. [CrossRef] [PubMed]

56. Pedro, M.T.; Antoniadis, G.; Scheuerle, A.; Pham, M.; Wirtz, C.R.; Koenig, R.W. Intraoperative High-Resolution Ultrasound and Contrast-Enhanced Ultrasound of Peripheral Nerve Tumors and Tumorlike Lesions. Neurosurg. Focus 2015, 39, E5. [CrossRef] [PubMed]

57. Chou, D.; Bilsky, M.H.; Luzzati, A.; Fisher, C.G.; Gokaslan, Z.L.; Rhines, L.D.; Dekutoski, M.B.; Fehlings, M.G.; Ghag, R.; Varga, P.; et al. Malignant Peripheral Nerve Sheath Tumors of the Spine: Results of Surgical Management from a Multicenter Study. J. Neurosurg. Spine 2017, 26, 291-298. [CrossRef]

58. Higham, C.S.; Steinberg, S.M.; Dombi, E.; Perry, A.; Helman, L.J.; Schuetze, S.M.; Ludwig, J.A.; Staddon, A.; Milhem, M.M.; Rushing, D.; et al. SARC006: Phase II Trial of Chemotherapy in Sporadic and Neurofibromatosis Type 1 Associated ChemotherapyNaive Malignant Peripheral Nerve Sheath Tumors. Sarcoma 2017, 2017, 8685638. [CrossRef]

59. Gronchi, A.; Ferrari, S.; Quagliuolo, V.; Broto, J.M.; Pousa, A.L.; Grignani, G.; Basso, U.; Blay, J.-Y.; Tendero, O.; Beveridge, R.D.; et al. Histotype-Tailored Neoadjuvant Chemotherapy versus Standard Chemotherapy in Patients with High-Risk Soft-Tissue Sarcomas (ISG-STS 1001): An International, Open-Label, Randomised, Controlled, Phase 3, Multicentre Trial. Lancet Oncol. 2017, 18, 812-822. [CrossRef]

60. Hirbe, A.C.; Cosper, P.F.; Dahiya, S.; Van Tine, B.A. Neoadjuvant Ifosfamide and Epirubicin in the Treatment of Malignant Peripheral Nerve Sheath Tumors. Sarcoma 2017, 2017, 3761292. [CrossRef]

61. Gronchi, A.; Stacchiotti, S.; Verderio, P.; Ferrari, S.; Martin Broto, J.; Lopez-Pousa, A.; Llombart-Bosch, A.; Dei Tos, A.P.; Collini, P.; Jurado, J.C.; et al. Short, Full-Dose Adjuvant Chemotherapy (CT) in High-Risk Adult Soft Tissue Sarcomas (STS): Long-Term Follow-up of a Randomized Clinical Trial from the Italian Sarcoma Group and the Spanish Sarcoma Group. Ann. Oncol. Off. J. Eur. Soc. Med. Oncol. 2016, 27, 2283-2288. [CrossRef]

62. Kroep, J.R.; Ouali, M.; Gelderblom, H.; Le Cesne, A.; Dekker, T.J.A.; Van Glabbeke, M.; Hogendoorn, P.C.W.; Hohenberger, P. First-Line Chemotherapy for Malignant Peripheral Nerve Sheath Tumor (MPNST) versus Other Histological Soft Tissue Sarcoma Subtypes and as a Prognostic Factor for MPNST: An EORTC Soft Tissue and Bone Sarcoma Group Study. Ann. Oncol. Off. J. Eur. Soc. Med. Oncol. 2011, 22, 207-214. [CrossRef] [PubMed]

63. Pervaiz, N.; Colterjohn, N.; Farrokhyar, F.; Tozer, R.; Figueredo, A.; Ghert, M. A Systematic Meta-Analysis of Randomized Controlled Trials of Adjuvant Chemotherapy for Localized Resectable Soft-Tissue Sarcoma. Cancer 2008, 113, 573-581. [CrossRef]

64. Marjanska, A.; Galazka, P.; Wysocki, M.; Styczynski, J. New Frontiers in Therapy of Peripheral Nerve Sheath Tumors in Patients with Neurofibromatosis Type 1: Latest Evidence and Clinical Implications. Anticancer Res. 2020, 40, 1817-1831. [CrossRef]

65. Carli, M.; Ferrari, A.; Mattke, A.; Zanetti, I.; Casanova, M.; Bisogno, G.; Cecchetto, G.; Alaggio, R.; De Sio, L.; Koscielniak, E.; et al. Pediatric Malignant Peripheral Nerve Sheath Tumor: The Italian and German Soft Tissue Sarcoma Cooperative Group. J. Clin. Oncol. Off. J. Am. Soc. Clin. Oncol. 2005, 23, 8422-8430. [CrossRef]

66. Kaplan, H.G.; Rostad, S.; Ross, J.S.; Ali, S.M.; Millis, S.Z. Genomic Profiling in Patients with Malignant Peripheral Nerve Sheath Tumors Reveals Multiple Pathways with Targetable Mutations. J. Natl. Compr. Cancer Netw. JNCCN 2018, 16, 967-974. [CrossRef] [PubMed]

67. Nagabushan, S.; Lau, L.M.S.; Barahona, P.; Wong, M.; Sherstyuk, A.; Marshall, G.M.; Tyrrell, V.; Wegner, E.A.; Ekert, P.G.; Cowley, M.J.; et al. Efficacy of MEK Inhibition in a Recurrent Malignant Peripheral Nerve Sheath Tumor. NPJ Precis. Oncol. $2021,5,9$. [CrossRef]

68. Sarcoma Alliance for Research through Collaboration. SARC031: A Phase 2 Trial of the MEK Inhibitor Selumetinib (AZD6244 Hydrogen Sulfate) in Combination with the MTOR Inhibitor Sirolimus for Patients with Unresectable or Metastatic Malignant Peripheral Nerve Sheath Tumors; National Library of Medicine: Bethesda, MD, USA, 2020.

69. Klesse, L.J.; Jordan, J.T.; Radtke, H.B.; Rosser, T.; Schorry, E.; Ullrich, N.; Viskochil, D.; Knight, P.; Plotkin, S.R.; Yohay, K. The Use of MEK Inhibitors in Neurofibromatosis Type 1-Associated Tumors and Management of Toxicities. Oncologist 2020, 25, e1109-e1116. [CrossRef]

70. Great Ormond Street Hospital for Children NHS Foundation Trust. A Paediatric Phase I/II Study of Intermittent Dosing of the Mek-1 Inhibitor Selumetinib in Children with Neurofibromatosis Type-1 and Inoperable Plexiform Neurofibroma and/or Progressive Optic Pathway Glioma; National Library of Medicine: Bethesda, MD, USA, 2021. 
71. National Cancer Institute (NCI). Phase II Trial of the MEK1/2 Inhibitor Selumetinib (AZD6244 Hydrogen Sulfate in Adults with Neurofibromatosis Type 1 (NF1) and Inoperable Plexiform Neurofibromas; National Library of Medicine: Bethesda, MD, USA, 2020.

72. SpringWorks Therapeutics, Inc. A Phase $2 b$ Trial of the MEK 1/2 Inhibitor (MEKi) PD-0325901 in Adult and Pediatric Patients with Neurofibromatosis Type 1 (NF1)-Associated Inoperable Plexiform Neurofibromas (PNs) That Are Causing Significant Morbidity; National Library of Medicine: Bethesda, MD, USA, 2021.

73. Yu, A.L.; Gilman, A.L.; Ozkaynak, M.F.; London, W.B.; Kreissman, S.G.; Chen, H.X.; Smith, M.; Anderson, B.; Villablanca, J.G.; Matthay, K.K.; et al. Anti-GD2 Antibody with GM-CSF, Interleukin-2, and Isotretinoin for Neuroblastoma. N. Engl. J. Med. 2010, 363, 1324-1334. [CrossRef]

74. Tap, W.D.; Demetri, G.; Barnette, P.; Desai, J.; Kavan, P.; Tozer, R.; Benedetto, P.W.; Friberg, G.; Deng, H.; McCaffery, I.; et al. Phase II Study of Ganitumab, a Fully Human Anti-Type-1 Insulin-like Growth Factor Receptor Antibody, in Patients with Metastatic Ewing Family Tumors or Desmoplastic Small Round Cell Tumors. J. Clin. Oncol. Off. J. Am. Soc. Clin. Oncol. 2012, 30, 1849-1856. [CrossRef] [PubMed]

75. Anderson, P.M.; Bielack, S.S.; Gorlick, R.G.; Skubitz, K.; Daw, N.C.; Herzog, C.E.; Monge, O.R.; Lassaletta, A.; Boldrini, E.; Pápai, Z.; et al. A Phase II Study of Clinical Activity of SCH 717454 (Robatumumab) in Patients with Relapsed Osteosarcoma and Ewing Sarcoma. Pediatr. Blood Cancer 2016, 63, 1761-1770. [CrossRef]

76. Sharif, S.; Ferner, R.; Birch, J.M.; Gillespie, J.E.; Gattamaneni, H.R.; Baser, M.E.; Evans, D.G.R. Second Primary Tumors in Neurofibromatosis 1 Patients Treated for Optic Glioma: Substantial Risks After Radiotherapy. J. Clin. Oncol. 2006, 24, $2570-2575$. [CrossRef]

77. Kahn, J.; Gillespie, A.; Tsokos, M.; Ondos, J.; Dombi, E.; Camphausen, K.; Widemann, B.C.; Kaushal, A. Radiation Therapy in Management of Sporadic and Neurofibromatosis Type 1-Associated Malignant Peripheral Nerve Sheath Tumors. Front. Oncol. 2014, 4, 324. [CrossRef]

78. Stucky, C.-C.H.; Johnson, K.N.; Gray, R.J.; Pockaj, B.A.; Ocal, I.T.; Rose, P.S.; Wasif, N. Malignant Peripheral Nerve Sheath Tumors (MPNST): The Mayo Clinic Experience. Ann. Surg. Oncol. 2012, 19, 878-885. [CrossRef]

79. Bishop, A.J.; Zagars, G.K.; Torres, K.E.; Bird, J.E.; Feig, B.W.; Guadagnolo, B.A. Malignant Peripheral Nerve Sheath Tumors: A Single Institution's Experience Using Combined Surgery and Radiation Therapy. Am. J. Clin. Oncol. 2018, 41, 465-470. [CrossRef] 